\title{
Whistleblowing or scaremongering?
}

\author{
R. Kirschen' and P. Mossey ${ }^{2}$
}

\author{
We live in a society of free speech but we, as dentists, are also \\ privileged to be members of a self regulated profession and, as such, \\ have responsibilities to fulfil. Dentists must be responsible for \\ supplying balanced information to the public, based on the best \\ evidence available.
}

would be necessary to provide convincing evidence?

There is undoubtedly room for improvement in the way that orthodontics is administered and carried out in the UK. However, it is a mature specialty with a strong academic base and respect for scientific evidence. The inference in the programme that specialist training supported by research is of doubtful relevance or validity confronts all dentists who value structured training and evidence based clinical practice. The message enshrined in the 'alternative' treatment philosophy is well known to all orthodontists. If this consistently delivered what it promises, there would be no controversy as orthodontists would all recognise the benefits.

No, this was not whistleblowing but an act of scaremongering, causing unwarranted anxiety in the minds of many thousands of parents and children. Scaremongering is not new to dentistry, as the media handling of the amalgam, frequency of dental examinations and fluoridation controversies has shown. In all these issues, scaremongering tactics continue to be used selectively to manipulate the vulnerable without any solid scientific evidence. with which facial proportions can be manipulated at will and by any amount, using expansion and functional appliances, is not supported by current evidence.

It may well be claimed that the opening statement in the programme, that 50 per cent of the children who undergo orthodontic treatment suffer facial damage, was an act of whistleblowing. This might imply that the programme was a way of identifying, and if possible helping, individual colleagues who are under-performing in some way. It must however be deemed irresponsible to attempt to blow the whistle on an entire discipline without robust scientific evidence.

\section{The need for evidence}

The resurrection of a treatment philosophy and techniques similar to those used in the first quarter of the last century (but later rejected) should be treated with great caution, at least until fresh evidence is produced to demonstrate definite advantages in terms of aesthetics or dental health while at the same time providing long term stability. After 25 years of being lobbied, are we not entitled to ask where are the clinical trials that

\section{Responsibilities}

We live in a society of free speech but we, as dentists, are also privileged to be members of a self regulated profession and, as such, have responsibilities to fulfil. However, the principle of self regulation is threatened by the irresponsible behaviour of some of its own members. Through its elected representative bodies, the profession must consider the issue of professional accountability when some of its members create unwarranted anxiety in the general population by engaging in negative campaigning and scaremongering.

Dentists must be responsible for supplying balanced information to the public, based on the best evidence available. Where there are new therapies, these should undergo rigorous scientific investigation. Regrettably, in the case of those who advocate the alternative approach to orthodontic treatment, attempts to gather the clinical records required for scientific scrutiny have been unsuccessful. Collaboration with research institutions thus remains elusive. 